ARTICLE

\title{
A concise access to bridged $[2,2,1]$ bicyclic lactones with a quaternary stereocenter via stereospecific hydroformylation
}

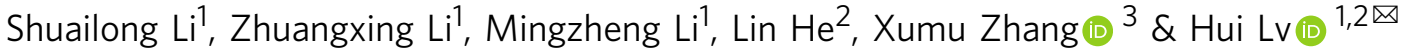

Chiral bridged $[2,2,1]$ bicyclic lactones are privileged structural units in pharmaceutics and bioactive nature products. However, the synthetic methods for these compounds are rare. Here we report an efficient method for enantioselective construction of bridged $[2,2,1]$ bicyclic lactones bearing a quaternary stereocenter via Rh-catalyzed asymmetric hydroformylation/intramolecular cyclization/pyridium chlorochromate (PCC) oxidation. By employing a hybrid phosphine-phosphite chiral ligand, a series of cyclopent-3-en-1-ols are transformed into corresponding $\gamma$-hydroxyl aldehydes with specific syn-selectivity. Then, hemiacetals form in situ and oxidation with PCC in one-pot affords bridged [2,2,1] bicyclic lactones in high yields and excellent enantiomeric excess. Replacing the hydroxyl group by an ester group, cyclopentanecarbaldehydes with a chiral all-carbon quaternary stereocenter in the $\gamma$-position can be generated efficiently.

\footnotetext{
${ }^{1}$ Key Laboratory of Biomedical Polymers of Ministry of Education \& College of Chemistry and Molecular Sciences, Engineering Research Center of Organosilicon Compounds \& Materials, Ministry of Education, Sauvage Center for Molecular Sciences, Wuhan University, Wuhan, China. ${ }^{2}$ Key Laboratory for Green Processing of Chemical Engineering of Xinjiang Bingtuan, School of Chemistry and Chemical Engineering, Shihezi University, Xinjiang Uygur Autonomous Region, Xinjiang, China. ${ }^{3}$ Grubbs Institute and Department of Chemistry, Southern University of Science and Technology, Shenzhen,

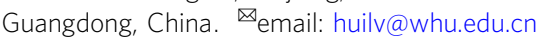


E nantiomeric bridged $[2,2,1]$ bicyclic lactone skeletons and their ring-opening products, cyclopentanols bearing two chiral centers, are important scaffolds widely occurring in both pharmaceutics and biology active compounds (Fig. 1) ${ }^{1,2}$. For example, chiral molecular DCK is a kind of anti-HIV agent ${ }^{3-5}$. Consequently, the synthesis of bridged $[2,2,1]$ bicyclic lactones received wide attentions and several approaches have been developed. The typical methods include Baeyer-Villiger oxidation $^{6}$, esterification ${ }^{7,8}$, halolactonization ${ }^{9,10}$, electrocatalytic reaction $^{11}$, and others ${ }^{12-14}$. However, most of these approaches focused on the synthesis of racemic bridged $[2,2,1]$ bicyclic lactones and multistep synthesis was necessary to achieve these transformations. To date, there are only two examples on the construction of chiral bridged $[2,2,1]$ bicyclic lactones in an enantioselective manner. In 2015, Dominguez developed a synthetic route to chiral bridged $[2,2,1]$ bicyclic lactones by using chiral alcohol as starting material (Fig. 2a) ${ }^{15}$. In 2018, Zhu et al. developed a copper-catalyzed enantioselective arylative desymmetrization reaction of prochiral cyclopentenes, and then followed by hydrolysis and intramolecular iodolactonlization to generate bridged $[2,2,1]$ bicyclic lactones. However, the installation and removal of an amide directing group were essential to this synthetic route, which resulted in relatively low atom economy (Fig. 2b) ${ }^{16}$. Therefore, the development of a concise and efficient method to produce bridged [2,2,1] bicyclic lactones is highly desirable.

Asymmetric hydroformylation (AHF) represents an efficient approach for asymmetric formation of $\mathrm{C}-\mathrm{C}$ bond in an atomic economic manner ${ }^{17-25}$, and the aldehyde products can be easily converted to versatile functional compounds, such as chiral alcohols, acids, amines and esters ${ }^{26-34}$, thus AHF has been widely investigated and some significant progresses have been made ${ }^{35-45}$. However, most of the work focused on the AHF of monosubstituted olefins and disubstituted alkenes, and only one chiral center was introduced into the product. As a result, the construction of chiral aldehydes containing a quaternary center and a tertiary center simultaneously by AHF is rarely exploited. To the best of our knowledge, there was only one report achieved this transformation by using desymmetric hydroformylation strategy, but the substrate scope was limited to cyclopropenes with high ring strain. Furthermore, only moderate to good enantioselectivities were obtained $(\leq 83 \% \mathrm{ee})^{46}$. Consequently, highly efficient synthesis of multichiral aldehydes bearing a quaternary stereocenter is still a problematic issue in this field.

Recently, our group developed a Rh-catalyzed AHF of 1,1disubstituted allyl alcohols to generate $\gamma$-butyrolactones ${ }^{47}$. We envisioned that the similar transformation might occur if 1-substituted cyclopent-3-en-1-ols were used as starting material, providing efficient access to bridged $[2,2,1]$ bicyclic lactones with a quaternary stereocenter. However, this transformation faces several challenges (Fig. 2c). First, it is very difficult to generate chiral aldehydes with exclusive syn-selectivity through AHF of 1-substituted cyclopent-3-en-1-ols, but it's an essential factor to form bridged $[2,2,1]$ bicyclic lactones in high yield. Moreover, the isomerization of alkene is difficult to be inhibited in AHF of cyclic olefines ${ }^{48-53}$, which further increases the difficulty of producing syn $\gamma$-hydroxyaldehydes. Second, the generation of the hemiacetals is unfavorable in this transformation because the large steric hindrance of tertiary alcohols greatly decreased the nucleophilic ability of hydroxy group to aldehydes. In addition, the relatively small steric difference between the two prochiral faces makes it difficult to obtain high enantioselectivity. Thus, the development of a highly efficient method for asymmetric synthesis of bridged $[2,2,1]$ bicyclic lactones containing a quaternary stereocenter is still a challenge.

Herein, we report one-pot synthesis of chiral bridged $[2,2,1]$ bicyclic lactones from readily available cyclopent-3-en-1-ols, delivering target products with good yields and high enantioselectivities, which provides efficient access to chiral bridged $[2,2,1]$ bicyclic lactones containing a quaternary stereocenter.

\section{Results and discussion}

Initially, considering only syn oxo-products can be transfered to corresponding bridged $[2,2,1]$ bicyclic lactones, AHF of $1 \mathbf{a}$ was investigated to obtain 2a stereospecifically. When $(S, S)-\mathrm{Ph}-\mathrm{BPE}$, the representative ligand in $\mathrm{AHF}^{54}$, was employed, 1a was transformed into oxo-product with high conversion and excellent ee, along with good diastereoselectivity (Table 1 , entry 1$)$. ( $R c, S p$ )Duanphos showed low activity in this transformaiton albeit with good stereocontrol (Table 1, entry 2). ( $R, R)$-Quinoxp, which performed well in asymmetric hydrogenation reactions ${ }^{55-59}$, afforded target product in low yield with moderate enantioselectivity (Table 1 , entry 3 ). The reaction was totally inhibitted when $(S, S)$-Me-Duphos and (S)-Segphos were employed (Table 1, a
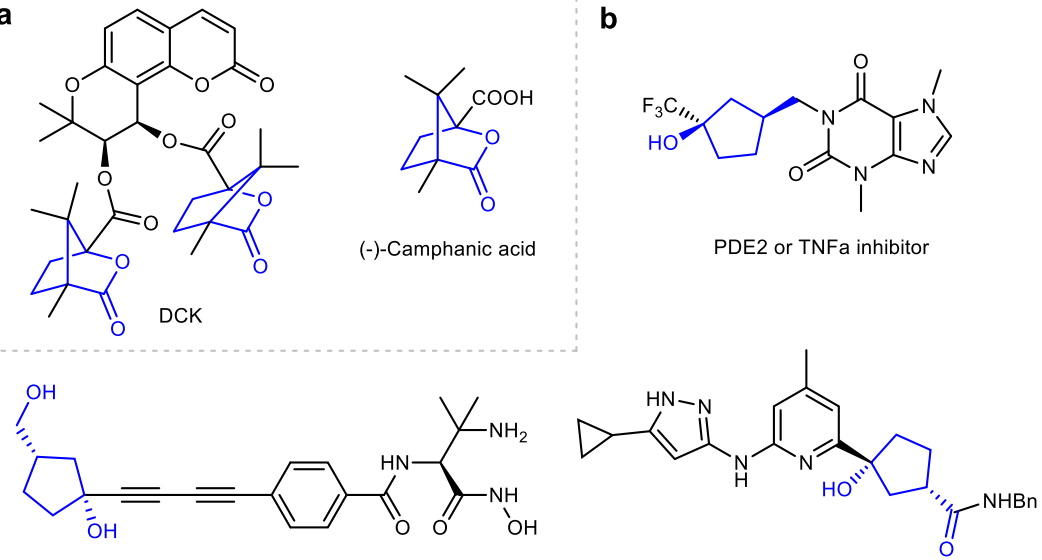

Inhibitor of LpxC in gram-negative bacteria b<smiles>Cn1cnc2c1c(=O)n(CC1CCC(O)(F)C1)c(=O)n2C</smiles>

(-)-Camphanic acid $\quad$ PDE2 or TNFa inhibitor

Inhibitor of RET

Fig. 1 Pharmaceutics and bioactive compounds containing bridged $[2,2,1]$ bicyclic lactones and their ring-opening derivatives. a Bioactive molecules containing bridged $[2,2,1]$ bicyclic lactones. b Ring-opening derivatives of bridged $[2,2,1]$ bicyclic lactones. 
a Preparation of bridged $[2,2,1]$ bicyclic lactones from chiral alcohols

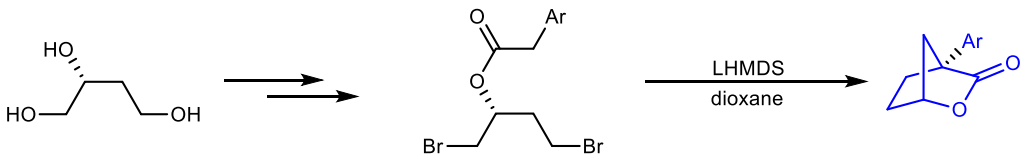

b Desymmetrization of prochiral cyclopentenes and iodolactonization to bridged $[2,2,1]$ bicyclic lactones
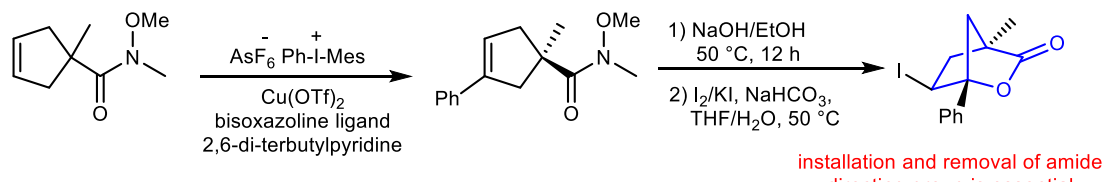
directing group is essential

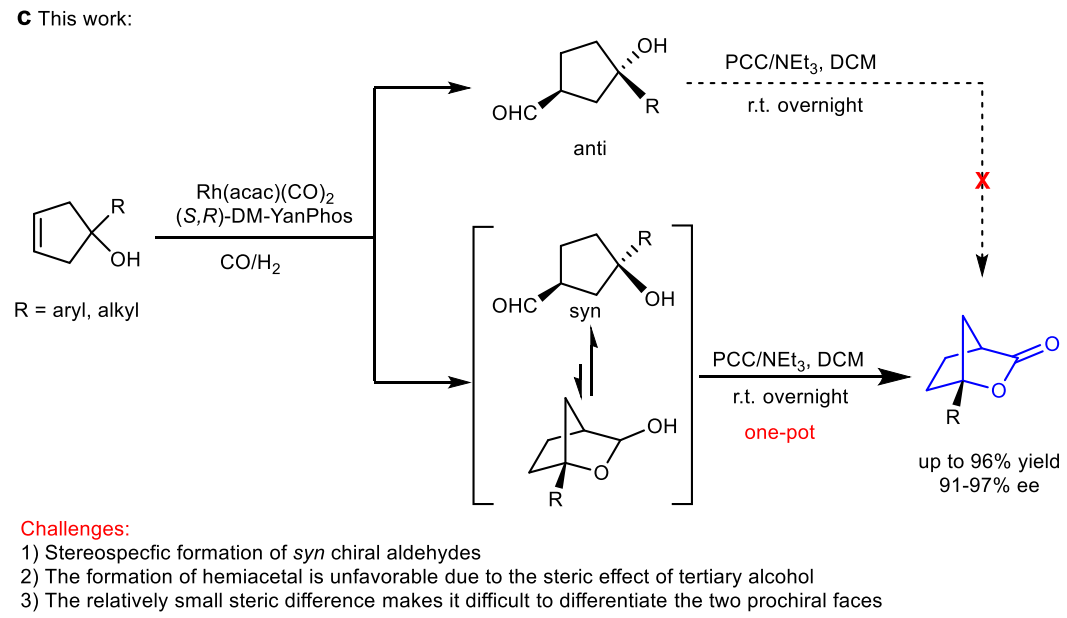

Fig. 2 Methods for synthesis of chiral bridged [2,2,1] bicyclic lactones. a Synthesis of bridged $[2,2,1]$ bicyclic lactones by using chiral alcohol as starting material. b Preparation of bridged $[2,2,1]$ bicyclic lactones by amide-directed Heck reaction and iodolactonization. c Stereopecific hydroformylation and lactonization to form bridged $[2,2,1]$ bicyclic lactones.

\section{Table 1 Ligand screening in the asymmetric hydroformylation of $1 a^{a}$.}

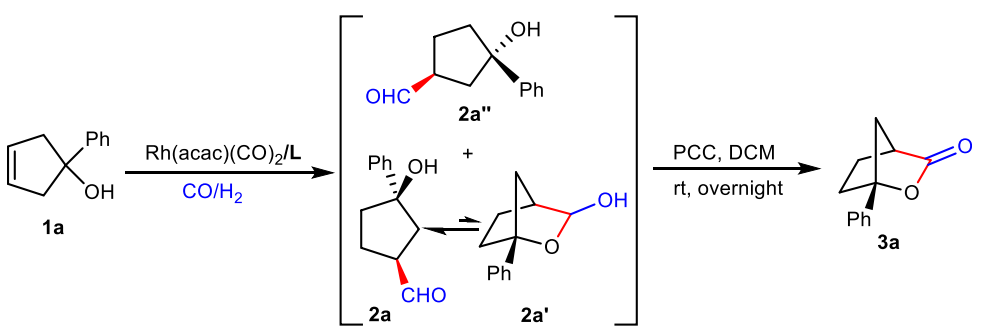

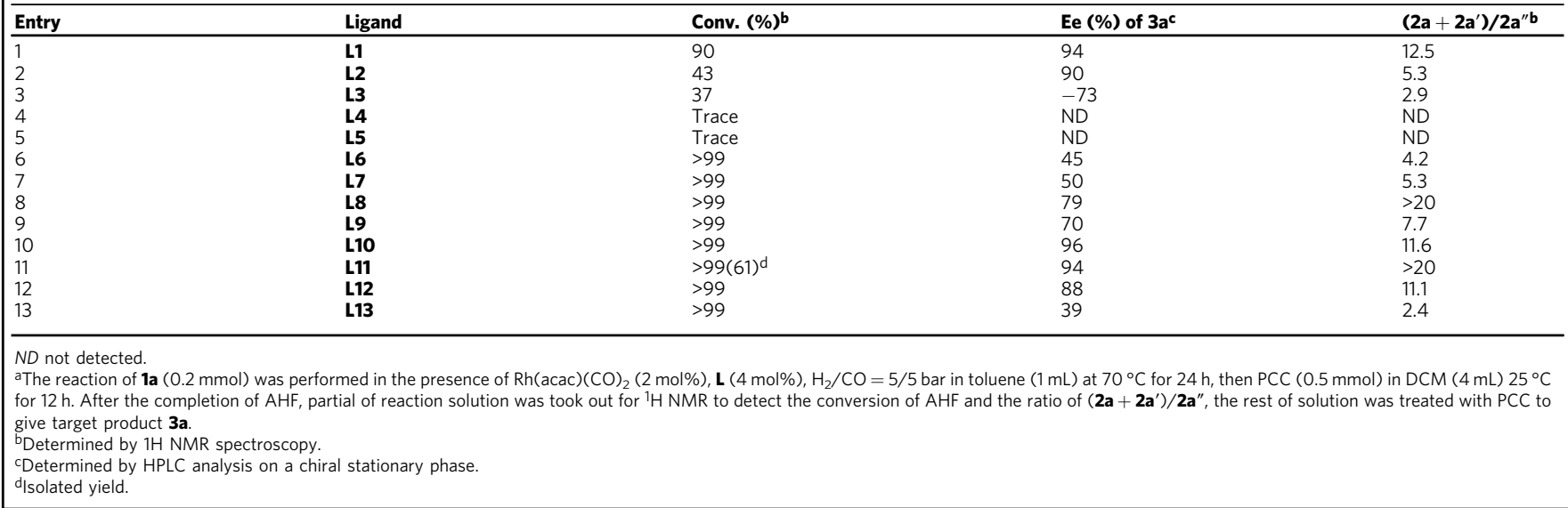


<smiles>c1ccc([PH+]C(CCP2[C@H](c3ccccc3)CC[C@H]2c2ccccc2)[PH2+]c2ccccc2)cc1</smiles>

L1 $(S, S)$-Ph-BPE<smiles>CC(C)(C)[Pb]1Cc2ccccc2[C@H]1[C@@H]1Cc2ccccc21</smiles>

L2 $\left(R_{\mathrm{C}}, S_{\mathrm{P}}\right)$-DuanPhos<smiles>CP(c1nc2ccccc2nc1P(C)[Pb](C)(C)C)C(C)(C)C</smiles>

L3 $(R, R)$-QuinoxP*<smiles>C[C@@H]1CC[C@H]2C[C@H]3CC[C@@H](C)P3c3ccccc3P21</smiles>

L4 (S,S)-Me-Duphos<smiles>Pc1ccccc1-c1ccc2c(c1-c1c(P)ccc3c1OCO3)OCO2</smiles>

L5 (S)-Segphos<smiles></smiles>

L6 $\mathrm{Ar}=\mathrm{C}_{6} \mathrm{H}_{5},(S, S)$-YanPhos

L7 $\mathrm{Ar}=3,5-\mathrm{Me}-\mathrm{C}_{6} \mathrm{H}_{3},(S, S)$-DM-YanPhos

L8 $\mathrm{Ar}=3,5-{ }^{\mathrm{t}} \mathrm{Bu}-\mathrm{C}_{6} \mathrm{H}_{3},(S, S)$-DTB-YanPhos

L9 $\mathrm{Ar}=3,5-{ }^{-} \mathrm{B}$ B-4-MeO- $\mathrm{C}_{6} \mathrm{H}_{2},(S, S)$-DTBM-YanPhos<smiles>CCCCc1ccc2ccccc2c1-c1c(N(Cc2ccccc2)POc2ccc3c(c2-c2c(OP(c4ccccc4)c4ccccc4)ccc4c2CCCC4)CCCC3)ccc2ccccc12</smiles>

L13 $(S, S)-\mathrm{H}_{8}-$ YanPhos<smiles>CCCCc1ccc2ccccc2c1-c1ccccc1N(Cc1ccccc1)POc1ccc2ccccc2c1-c1c(OP(=O)(c2ccccc2)c2ccccc2)ccc2ccccc12</smiles>

L10 $\mathrm{Ar}=\mathrm{C}_{6} \mathrm{H}_{5},(S, R)$-YanPhos

L11 $\mathrm{Ar}=3,5-\mathrm{Me}-\mathrm{C}_{6} \mathrm{H}_{3},(S, R)$-DM-YanPhos

L12 $\mathrm{Ar}=3,5-{ }^{\mathrm{t}} \mathrm{Bu}-\mathrm{C}_{6} \mathrm{H}_{3},(S, R)$-DTB-YanPhos

Fig. 3 Ligands evaluation for asymmetric hydroformylation of 1a. L1-L5 are commercially available diphosphine ligands, L6-L13 are Yanphos-type ligands developed in our lab.

Table 2 Additive screening in the PCC oxidationa.

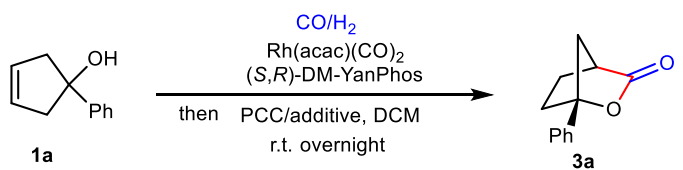

\begin{tabular}{llll}
\hline Entry & Additive & Yield (\%) & Ee (\%) [b] \\
\hline 1 & - & 61 & 94 \\
$2^{\mathrm{c}}$ & - & 56 & 94 \\
3 & $\mathrm{AcOH}$ & 26 & 94 \\
4 & $\mathrm{NaOAc} \bullet 3 \mathrm{H}_{2} \mathrm{O}$ & 49 & 94 \\
5 & $\mathrm{~K}_{2} \mathrm{CO}_{3}$ & 82 & 94 \\
6 & $\mathrm{Cs}_{2} \mathrm{CO}_{3}$ & 85 & 94 \\
7 & $\mathrm{NEt}_{3}$ & 90 & 94 \\
8 & $\mathrm{NaOH}$ & 40 & 80
\end{tabular}

aThe reaction of $\mathbf{1 a}(0.2 \mathrm{mmol})$ was performed in the presence of Rh(acac) $(\mathrm{CO})_{2}(2 \mathrm{~mol} \%), \mathbf{L 1 1}(4 \mathrm{~mol} \%), \mathrm{H}_{2} / \mathrm{CO}=5 / 5$ bar in toluene $(1 \mathrm{~mL})$ at $70{ }^{\circ} \mathrm{C}$ for $24 \mathrm{~h}$, The reaction was cooled to room temperature and the pressure was carefully released in a well-ventilated hood, then the mixture was treated with PCC $(0.5 \mathrm{mmol})$, additive $(0.1 \mathrm{mmol})$ in DCM $(4 \mathrm{~mL}) 25^{\circ} \mathrm{C}$ for $12 \mathrm{~h} \mathrm{in} \mathrm{one} \mathrm{pot.}$ betermined by HPLC analysis on a chiral stationary phase.

CPerformed at $40^{\circ} \mathrm{C}$.

entries 4-5). In order to obtain higher enantio- and diastereoselectivity, a series of YanPhos-type ligands with different axial chirality (Fig. 3), which were developed by our group, were evaluated $^{60-63}$. The results showed that all YanPhos-type ligands had good catalytic activity for this transformation, but there were big differences in the control of enantioselectivity and diastereoselectivity. Generally, YanPhos containing $(S, R)$ axial chirality had better perfomance than that of YanPhos with $(S, S)$ axial chirality (Table 1, entries 6-13). When $(S, R)$-DM-YanPhos was employed (Table 1, entry 11), the target product was obtained with the best diastereo- and enenatioselectivity.
Having established the optimized reaction condition for AHF of 1a, we attempt to synthesize bridged [2,2,1] bicyclic lactone $\mathbf{3 a}$ in one pot by sequential AHF/intramolecular cyclization/dehydrogenation oxidation (Table 2). Based on our previous work ${ }^{64}$, PCC (pyridinium chlorochromate) was selected as oxidant and delivered target product 3a with moderate yield (entry 1). Increasing reaction temperature could not improve the yield (entry 2). Considering the bulky steric hindrance greatly decreased the nucleophilicity of tertiary alcohol ${ }^{65}$, several additives were screened to promote the cyclization of $\mathbf{2 a}$. Acetic acid lead to a significant drop in yield, $\mathrm{NaOAc}$ resulted in the decrease 


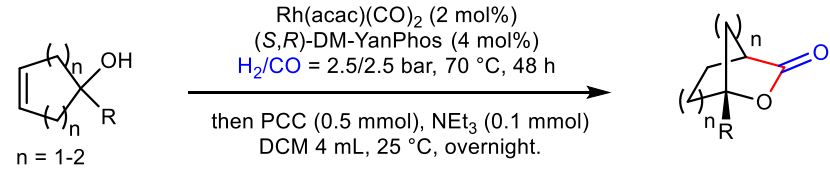<smiles>O=C1Oc2ccccc2C1C1CC1</smiles>

$3 a$ $90 \%$ yield, $95 \%$ ee<smiles>O=C1O[C@@]2(c3ccccc3Cl)CCC1C2</smiles>

$3 e$ $90 \%$ yield, $94 \%$ ee<smiles>Cc1cccc([C@]23CCC(C2)C(=O)O3)c1</smiles>

$3 \mathbf{j}$ $83 \%$ yield, $94 \%$ ee<smiles></smiles><smiles>O=C1O[C@]2(C3CCCC3)CCC1C2</smiles>

3t
$89 \%$ yield, $96 \%$ ee

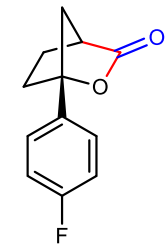

3b

$81 \%$ yield, $95 \%$ ee<smiles>O=C1O[C@@]2(c3ccc(Cl)c(Cl)c3)CCC1C2</smiles>

$3 f$

$82 \%$ yield, $95 \%$ ee<smiles>COc1ccccc1C12CCC(CC1)C(=O)O2</smiles>

3k

$47 \%$ yield, $91 \%$ ee

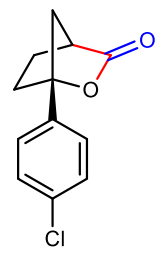

3c

$96 \%$ yield, $95 \%$ ee<smiles>COc1cccc(C23CCC(CC2)C(=O)O3)c1</smiles>

$\stackrel{3 \mathbf{g}}{90 \% \text { yield, } 96 \% \text { ee }}$<smiles>O=C1OC(c2ccc(C(F)(F)F)cc2)C2CCC1C2</smiles>

3I

$77 \%$ yield, $95 \%$ ee

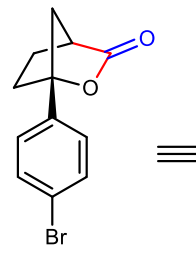

3d

95\% yield, $96 \%$ ee<smiles>O=C1OC(c2ccc(Br)cc2)C2CCC1C2</smiles>

3h

$80 \%$ yield, $94 \%$ ee<smiles>O=C1OC2(c3ccc(-c4ccccc4)cc3)CCC1CC2</smiles>

$3 \mathrm{~m}$

71\% yield, $94 \%$ ee $90 \%$ yield, $96 \%$ ee<smiles>CC(C)C12C=CC(C1)OC2=O</smiles>

$3 \mathbf{q}$<smiles>O=C1OC2(CCCC2)CC2CC3CCC1C3C2</smiles>

$3 \mathbf{v}$

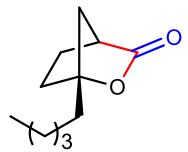

$60 \%$ yield, $91 \%$ ee

$2 \mathbf{w ~ d r}>20: 1$ $78 \%$ yield, $93 \%$ ee<smiles>O=C[C@@H]1CC[C@](O)(C(F)(F)F)C1</smiles>

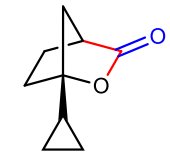<smiles>Cc1cc([N+](=O)[O-])cc(C23CCC(CC2)C(=O)O3)c1</smiles>
$73 \%$ yield, $94 \%$ ee<smiles></smiles>

$79 \%$ yield, $96 \%$ ee

3s $87 \%$ yield, $96 \%$ ee<smiles>O=C1O[C@]2(c3ccccc3)CCC[C@H]1CC2</smiles>

$3 \mathbf{x}$

$80 \%$ yield, $85 \%$ ee

Fig. 4 Scope of 1-substituted cyclopent-3-en-1-ols and 1-phenylcyclohept-4-en-1-ol. Reaction conditions: The reaction of 1a (0.2 mmol) was performed in the presence of $\mathrm{Rh}(\mathrm{acac})(\mathrm{CO})_{2}(2 \mathrm{~mol} \%), \mathbf{L 1 1}(4 \mathrm{~mol} \%), \mathrm{H}_{2} / \mathrm{CO}=2.5 / 2.5$ bar in toluene $(1 \mathrm{~mL})$ at $70{ }^{\circ} \mathrm{C}$ for $48 \mathrm{~h}$, The reaction was cooled to room temperature and the pressure was carefully released in a well-ventilated hood, then the mixture was treated with $\mathrm{PCC}(0.5 \mathrm{mmol}), \mathrm{Et}_{3} \mathrm{~N}(0.1 \mathrm{mmol})$ in DCM $(4 \mathrm{~mL})$ at $25^{\circ} \mathrm{C}$, overnight. $\mathrm{NA}=$ not available.

of yield to some extent. To our delight, $\mathrm{K}_{2} \mathrm{CO}_{3}, \mathrm{Cs}_{2} \mathrm{CO}_{3}$ and $\mathrm{NEt}_{3}$ can promote this reaction, affording target product in high yield without compromising the enantioselectivity (entries 5-7). However, a racemization occurred when $\mathrm{NaOH}$ was used, resulting in the decrease of ee and dr values (entry $8,40 \%$ yield, $80 \%$ ee). Thus, one practical method for synthesis of bridged $[2,2,1]$ bicyclic lactones was most effective with $(S, R)$-DMYanPhos as the ligand in AHF and $\mathrm{NEt}_{3}$ as additive in PCC oxidation.
Under the optimal conditions, we investigated the substrate scope. All the bridged $[2,2,1]$ bicyclic lactones were prepared in good yields with excellent enantioselectivities (Fig. 4). Substrates bearing halides on the phenyl ring performed well in this transformation, giving target products with high yields and excellent ee's (3b-3f). The absolute configuration of $\mathbf{3 d}$ was confirmed by X-ray crystallographic analysis. Electron-donating and electronwithdrawing substituted groups on the phenyl ring were also tolerated, furnishing $\mathbf{3 f}, \mathbf{3} \mathbf{g}, \mathbf{3 h}, \mathbf{3 i}, \mathbf{3} \mathbf{j}$ with high yields and 


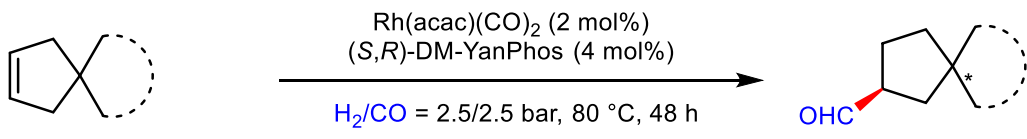

4

5<smiles>CC(=O)[C@]1(c2ccccc2)CC[C@@H](C=O)C1</smiles>

5a, $d r=9: 1$ $80 \%$ yield, $94 \%$ ee<smiles>O=C[C@H]1CC[C@]2(CCOC2=O)C1</smiles>

5b, $d r>20: 1$ $81 \%$ yield, $94 \%$ ee<smiles>O=C[C@H]1CC[C@]2(CCCOC2=O)C1</smiles>

5c, $d r>20: 1$ $86 \%$ yield, $87 \%$ ee

Fig. 5 Substrates for synthesis of chiral aldehydes with an all-carbon quaternary stereocenter. Reaction conditions: $4(0.2 \mathrm{mmol}), \mathrm{Rh}(\mathrm{acac})(\mathrm{CO}){ }_{2}(2 \mathrm{~mol}$ $\%)$, L11 $(4 \mathrm{~mol} \%), \mathrm{H}_{2} / \mathrm{CO}=2.5 / 2.5$ bar, toluene $(1 \mathrm{~mL}), 80^{\circ} \mathrm{C}$, $48 \mathrm{~h}$. The dr value of $\mathbf{5 a}-\mathbf{5 c}$ were determined by ${ }^{1} \mathrm{H}$ NMR spectroscopy.

a Gram-scale reaction of $\mathbf{1 d}$<smiles>OC1(c2ccc(Br)cc2)CC=CC1</smiles>

$1 \mathrm{~d}, 5 \mathrm{mmol}, 1.2 \mathrm{~g}$
1) $\mathrm{Rh}(\mathrm{acac})(\mathrm{CO})_{2} / \mathrm{L} 11$ $\mathrm{H}_{2} / \mathrm{CO}, \mathrm{PhMe}, 70^{\circ} \mathrm{C}$

2) PCC, $\mathrm{NEt}_{3}, \mathrm{DCM}$

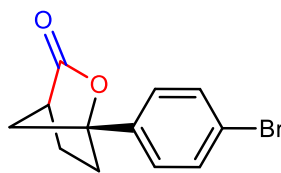

3d, $0.98 \mathrm{~g}$

$71 \%$ yield, $96 \%$ ee

b Transformation of $\mathbf{3 d}$ to alkyne, alkene, amide

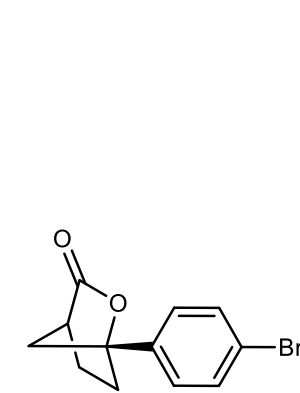

3d, $96 \%$ ee

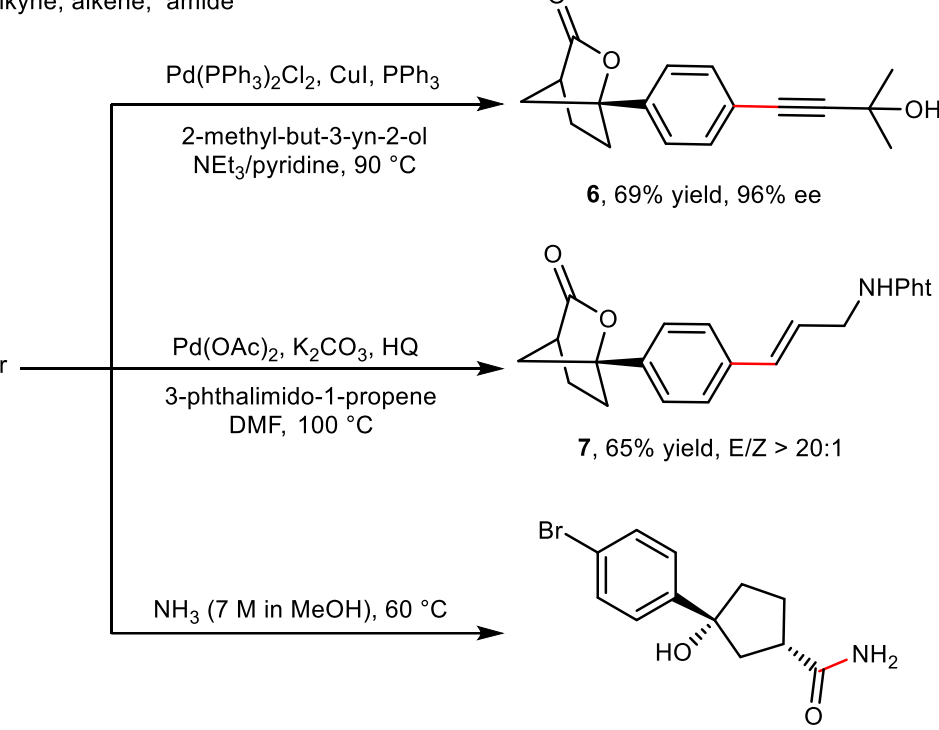

$8,92 \%$ yield, $96 \%$ ee

C Transformation of $2 \mathbf{a}$ to alcohol<smiles>O=C[C@H]1CC[C@@](O)(c2ccccc2)C1</smiles>

2a
$\mathrm{NaBH}_{4}, \mathrm{MeOH}, 0^{\circ} \mathrm{C}$

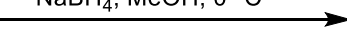

9, $99 \%$ yield, $95 \%$ ee

d Transformation of $\mathbf{2 m}$ to acid<smiles>O=C[C@H]1CC[C@@](O)(c2ccc(-c3ccccc3)cc2)C1</smiles>

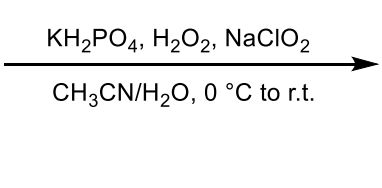<smiles>O=C(O)[C@H]1CC[C@@](O)(c2ccc(-c3ccccc3)cc2)C1</smiles>

$10,67 \%$ yield, $97 \%$ ee

Fig. 6 Gram-scale reaction and transformations of oxo-products and ring-opening reaction of bridged [2,2,1] bicyclic lactones. a Gram-scale reaction. b Transformation of $\mathbf{3} \mathbf{d}$ to corresponding alkyne, alkene and amide. c Reduction of $\mathbf{2} \mathbf{a}$ to alcohol. $\mathbf{d}$ Oxidation of $\mathbf{2} \mathbf{m}$ to acid. 
a

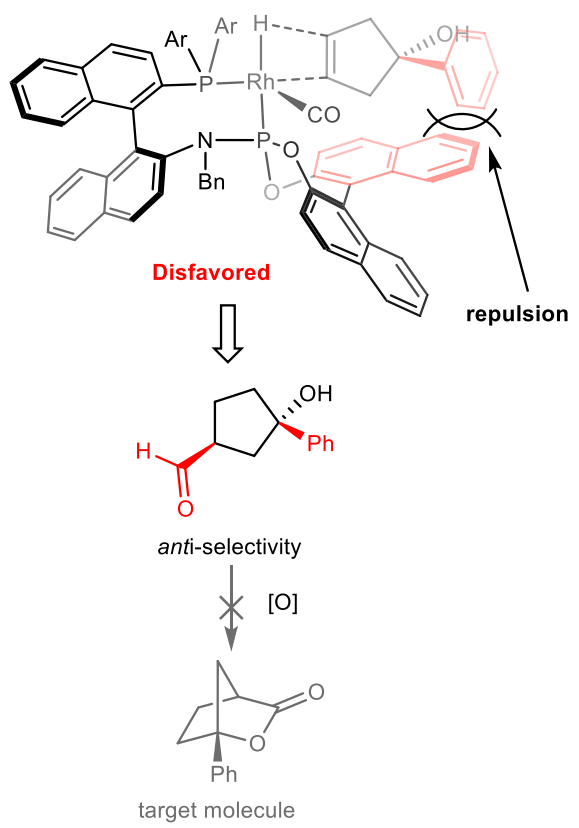

b

Model B
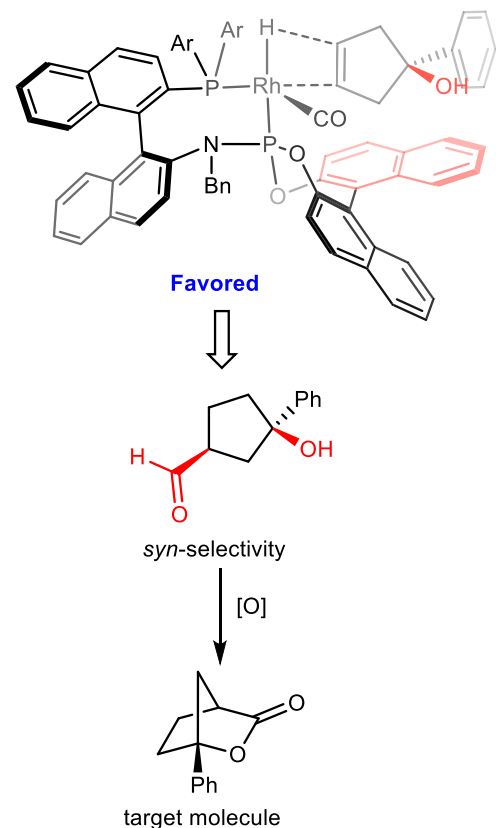

Fig. 7 Proposed stereochemical model. a Disfavored stereochemical model. b Favored stereochemical model.

excellent enantioselectivities, respectively. The yield of $\mathbf{3 k}$ was dropped sharply due to the ortho effect of methoxy group, but the high enantioselectivity was remained. In addition, functional groups, such as trifloromethyl, phenyl and borate (31-3n) on the para-position of the benzene ring were compatible, and the corresponding products were afforded with moderate to good yields and high ee's. Replacing phenyl by a naphthyl group (3o), the reaction also proceeded smoothly, providing the desired compound with high yield and excellent ee. Notably, alkyl substituents, such as benzyl, $n$-hexyl, isopropyl, cyclopropyl, cyclopentyl and cyclohexyl were also well tolerated in this transformation, delivering bridged $[2,2,1]$ bicyclic lactones with excellent ee's and high yields (3p-3u). Cyclopent-3-en-1-ol bearing a bulky sterically hindered damantyl group also proceeded effectively, affording target product with high yield (3v). Moreover, the oxo-product $\mathbf{2} \mathbf{w}$ was produced with high diastereoselectivity and excellent enantioselectivity ${ }^{66}$. Interestingly, 1phenylcyclohept-4-en-1-ol, a challenge substrate for AHF because of the substituent far away from reaction site, which made it difficult to control the stereoselectivity, also worked very well in this transformation, delivering 6-oxabicyclo[3.2.2]nonan-7-one $3 \mathbf{x}$ with high yield and good enantioselectivity.

Encouraged by the success of desymmetric strategy for construction of chiral bridged [2,2,1] bicyclic lactones with a $\mathrm{O}$-subsitituted quaternary center, primary exploration on efficient synthesis of cyclopentanecarbaldehyde with an all-carbon quaternary stereocenter was conducted. As shown in Fig. 5, when symmetric cyclopentene with phenyl and ester substituents was employed, the desired chiral aldehyde $\mathbf{5} \mathbf{a}$ was generated in good yield with high diastereo- and enantioselectivity. Moreover, allcarbon substituted chiral spiro-lactones could also be efficiently synthesized by this strategy, delivering target products with good yields and high enantioselectivities $(\mathbf{5 b}, \mathbf{5 c})$.

To further demonstrate the practical utility of this methodology, a gram-scale reaction of $\mathbf{1 d}$ was conducted in the presence of $0.2 \mathrm{~mol} \%$ catalyst, then treated with $\mathrm{NEt}_{3}$ and PCC, 3d was obtained with high yield and without any loss in enantioselectivity (Fig. 6a). Under the classical conditions of Sonogashira reaction and Heck reaction, alkyne and alkene groups were effectively incorporated into $\mathbf{3 d}$, and the chiral bridged [2,2,1] bicyclic lactone skeleton was not affected (Fig. 6b). In order to obtain the ring-opening derivatives of bridged [2,2,1] bicyclic lactones, 3d was treated with methanol solution of ammonia, furnishing chiral amide $\mathbf{8}$ with high yield and excellent ee (Fig. 6b). The hydroformylation product 2 a can be efficiently reducted by $\mathrm{NaBH}_{4}$, affording chiral dual alcohol 9 in high yield (Fig. 6c). Under a mild condition, the bioactive chiral acid 10 was readily prepared by oxidation of $2 \mathbf{m}$ with $\mathrm{H}_{2} \mathrm{O}_{2}$ and $\mathrm{NaClO}_{2}$ (Fig. 6d) ${ }^{67}$.

Based on the experimental results and the related mechanisum studies on Rh/Yanphos catalyzed AHF in literature ${ }^{27,61}$, we proposed the possible stereochemical model to explain the reason for high stereoselectivity in this transformation. According to the orientation of substrate closed to the catalyst, there are two possible coordination models (Fig. 7). In model A, there is a large repulsion between the benzene ring of the substrate and the naphthalene ring of ligand, hence this model is disfavored. By comparison, the repusion betweeen substrate and catalyst is much smaller in model B due to the small streric hindrance of hydroxy group, thus the asymmetric hydrofomylation reaction occurred smoothly, delivering chiral $\gamma$-hydroxyaldehyde with excellent synselectivity, which can be efficiently transfer to the target bridged $[2,2,1]$ bicyclic lactone in the presence of PCC.

In this work, we have developed an efficient and concise method for preparing bridged $[2,2,1]$ bicyclic lactones bearing a quaternary stereocenter from readily available starting material by one-pot process. This methodology shows excellent substrate compatibility and excellent stereocontrol, giving target products with high yields and excellent enantioselectivities. In addtion, this protocol also provides a useful strategy for construction of chiral aldehydes with an all-carbon quaternary stereocenter. Gram-scale reaction and diverse transformations of the oxo-products and bridged [2,2,1] bicyclic lactones demonstrate the utility of this method in synthetic chemistry. Further exploration on the 
construction of quaternary chiral center by AHF is ongoing in our laboratory.

\section{Methods}

In a glovebox filled with argon, to a $5 \mathrm{~mL}$ vial equipped with a magnetic bar was added $(S, R)$-DM-YanPhos $(0.004 \mathrm{mmol})$ and $\mathrm{Rh}(\mathrm{acac})(\mathrm{CO})_{2}(0.002 \mathrm{mmol}$ in $1 \mathrm{~mL}$ toluene). After stirring for $10 \mathrm{~min}$, the mixture was charged to substrate $(0.2 \mathrm{mmol})$. The vial was transferred into an autoclave and taken out of the glovebox. The argon gas was replacement with hydrogen gas for three times, and then hydrogen $(2.5 \mathrm{bar})$ and carbon monoxide $(2.5 \mathrm{bar})$ were charged in sequence. The reaction mixture was stirred at $70^{\circ} \mathrm{C}$ (oil bath) for $48 \mathrm{~h}$. The reaction was cooled to room temperature and the pressure was carefully released in a well-ventilated hood. The solution was transferred into a solution of PCC $(0.5 \mathrm{mmol})$ and triethylamine $(0.1 \mathrm{mmol})$ in $4 \mathrm{~mL}$ dichloromethane, the reaction mixture was stirred at $25^{\circ} \mathrm{C}$ (oil bath) overnight. The solution was concentrated and the product was isolated by column chromatography using petrol ether/EtOAc (30:1-10:1) as eluent to give the desired product.

\section{Data availability}

The data supporting the findings of this study are available in the paper and its Supplementary Information, further data are available from the corresponding author on request. The X-ray crystallographic coordinates for structures reported in this study have been deposited at the Cambridge Crystallographic Data Centre (CCDC), under deposition numbers CCDC 2034549 (3d). These data can be obtained free of charge from the Cambridge Crystallographic Data Centre via www.ccdc.cam.ac.uk/data_request/cif.

Received: 11 January 2021; Accepted: 10 August 2021; Published online: 06 September 2021

\section{References}

1. Patterson, B. D. et al. World patent WO2013170030 (2013).

2. Brubaker J. D., Dipietro L. V. World patent WO2018022761 (2018).

3. Xie, L. et al. Development and Preclinical Studies of Broad-Spectrum AntiHIV Agent $\left(3^{\prime} \mathrm{R}, 4^{\prime} \mathrm{R}\right)$-3-Cyanomethyl-4-methyl-3',4'-di-O-(S)-camphanoyl(+)-cis-khellactone (3-Cyanomethyl-4-methyl-DCK). J. Med. Chem. 51, 7689-7696 (2008).

4. Xie, L., Allaway, G., Wild, C., Kilgore, N. \& Lee, K.-H. Anti-AIDS Agents. Part 47: Synthesis and Anti-HIV Activity of 3-Substituted 3', $4^{\prime}$-Di-O-(S)camphanoyl- $\left(3^{\prime} \mathrm{R}, 4^{\prime} \mathrm{R}\right)-(+)$-cis-khellactone 3. Derivatives. Bioorg. Med. Chem. Lett. 11, 2291-2293 (2001).

5. Zhuang, X.-M. et al. Metabolism of novel anti-HIV agent 3-cyanomethyl-4methyl-DCK by human liver microsomes and recombinant CYP enzymes. Acta Pharmacol. Sin. 32, 1276-1284 (2011).

6. Yadav, J. S., Reddy, B. V. S., Basak, A. K. \& Narsaiah, A. V. Baeyer-Villiger Oxidations in Ionic Liquids. A Facile Conversion of Ketones to Esters and Lactones. Chem. Lett. 33, 248-249 (2004).

7. Johansson, P. O. et al. Potent inhibitors of the hepatitis C virus NS3 protease: Use of a novel P2 cyclopentane-derived template. Bioorg. Med. Chem. 14, 5136-5151 (2006).

8. Bindra, J. S., Grodski, A., Schaaf, T. K. \& Corey, E. J. New Extensions of the Bicyclo[2.2.1] heptane Route to Prostaglandins. J. Am. Chem. Soc. 95, 7522-7523 (1973).

9. Oppolzer, W. \& Cunningham, A. F. Total synthesis of ( \pm )chokol-A via an intramolecular type-I-magnesium ene reaction. Tetrahedron Lett. 27, 5467-5470 (1986).

10. Lomba, L., Afarinkia, K. \& Vinader, V. A new route to tricyclane sesquiterpenoids: total synthesis of $\alpha$-ekasantalic acid. Org. Biomol. Chem. 17, 4456-4459 (2019).

11. Batanero, B., Recio, J. \& Barba, F. One-pot anodic lactonization of Fenchone and Menthone and electrosynthesis of a new magnolione analogue. Electrochem. Commun. 66, 29-33 (2016).

12. Zhang, A. \& Nie, J. Enantioselective Synthesis of the Female Sex Pheromone of the Pink Hibiscus Mealybug, Maconellicoccus hirsutus. J. Agric. Food Chem. 53, 2451-2455 (2005)

13. Zhang, A., Nie, J. \& Khrimian, A. Chiral synthesis of maconelliol: a novel cyclobutanoid terpene alcohol from pink hibiscus mealybug, Maconellicoccus hirsutus. Tetrahedron Lett. 45, 9401-9403 (2004).

14. Hizuka, M., Fang, C., Suemune, H. \& Sakai, K. A Stereocontrolled Synthesis of Trisubstituted Cyclohexanes and Cyclopentanes. Its Application to the Synthesis of 11-Deoxyprostaglandins. Chem. Pharm. Bull. 37, 1185-1187 (1989).

15. Penrose, S. D. et al. Inter- and Intramolecular Annulation Strategies to a Cyclopentanone Building Block Containing an All-Carbon Quaternary Stereogenic Center. Org. Lett. 17, 1401-1404 (2015).
16. Wu, H., Wang, Q. \& Zhu, J. Copper-Catalyzed Enantioselective Arylative Desymmetrization of Prochiral Cyclopentenes with Diaryliodonium Salts. Angew. Chem. Int. Ed. 57, 2721-2725 (2018).

17. Agbossou, F., Carpentier, J.-F. \& Mortreux, A. Asymmetric Hydroformylation. Chem. Rev. 95, 2485-2506 (1995).

18. Breit, B. \& Seiche, W. Recent Advances on Chemo-, Regio- and Stereoselective Hydroformylation. Synthesis 1, 1-36 (2001).

19. Klosin, J. \& Landis, C. R. Ligands for Practical Rhodium-Catalyzed Asymmetric Hydroformylation. Acc. Chem. Res. 40, 1251-1259 (2007)

20. Franke, R., Selent, D. \& Börner, A. Applied Hydroformylation. Chem. Rev. 112, 5675-5732 (2012).

21. Jia, X., Wang, Z., Xia, C. \& Ding, K. Recent Advances in Rh-Catalyzed Asymmetric Hydroformylation of Olefins. Chin. J. Org. Chem. 33, 1369-1381 (2013).

22. Chikkali, S. H., van der Vlugt, J. I. \& Reek, J. N. H. Hybrid diphosphorus ligands in rhodium catalysed asymmetric hydroformylation. Coord. Chem. Rev. 262, 1-15 (2014)

23. Deng, Y., Wang, H., Sun, Y. \& Wang, X. Principles and Applications of Enantioselective Hydroformylation of Terminal Disubstituted Alkenes. ACS Catal. 5, 6828-6837 (2015).

24. Brezny, A. C. \& Landis, C. R. Recent Developments in the Scope, Practicality, and Mechanistic Understanding of Enantioselective Hydroformylation. Acc. Chem. Res. 51, 2344-2354 (2018).

25. Li, S., Li, Z., You, C., Lv, H. \& Zhang, X. Recent Advances in Asymmetric Hydroformylation. Chin. J. Org. Chem. 39, 1568-1582 (2019).

26. Zhang, X., Cao, B., Yu, S. \& Zhang, X. Rhodium-Catalyzed Asymmetric Hydroformylation of N-Allylamides: highly Enantioselective Approach to $\beta^{2}$ Amino Aldehydes. Angew. Chem. Int. Ed. 49, 4047-4050 (2010).

27. You, C. et al. Rhodium-Catalyzed Desymmetrization by Hydroformylation of Cyclopentenes: Synthesis of Chiral Carbocyclic Nucleosides. Angew. Chem. Int. Ed. 55, 6511-6514 (2016).

28. Tanaka, R., Nakano, K. \& Nozaki, K. Synthesis of $\alpha$-Heteroarylpropanoic Acid via Asymmetric Hydroformylation Catalyzed by Rh(I)-(R,S)BINAPHOS and the Subsequent Oxidation. J. Org. Chem. 72, 8671-8676 (2007).

29. Zhang, X., Cao, B., Liu, T.-L. \& Zhang, X. Rhodium-Catalyzed Asymmetric Hydroformylation of 1,1-Disubstituted Allylphthalimides: A Catalytic Route to 33 -Amino Acids. Adv. Synth. Catal. 355, 679-684 (2013).

30. Worthy, A. D., Joe, C. L., Lightburn, T. E. \& Tan, K. L. Application of a Chiral Scaffolding Ligand in Catalytic Enantioselective Hydroformylation. J. Am. Chem. Soc. 132, 14757-14759 (2010).

31. Joe, C. L., Blaisdell, T. P., Geoghan, A. F. \& Tan, K. L. Distal-Selective Hydroformylation using Scaffolding Catalysis. J. Am. Chem. Soc. 136, 8556-8559 (2014).

32. You, C. et al. Silicon-oriented regio- and enantioselective rhodium-catalyzed hydroformylation. Nat. Commun. 9, 2045 (2018).

33. Wong, G. W. \& Landis, C. R. Iterative Asymmetric Hydroformylation/Wittig Olefination Sequence. Angew. Chem. Int. Ed. 52, 1564-1567 (2013).

34. Li, S. et al. Rhodium-Catalyzed Enantioselective Anti-Markovnikov Hydroformylation of $\alpha$-Substituted Acryl Acid Derivatives. Org. Lett. 22, $1108-1112(2020)$

35. Sakai, N., Mano, S., Nozaki, K. \& Takaya, H. Highly enantioselective hydroformylation of olefins catalyzed by new phosphine phosphiterhodium(I) complexes. J. Am. Chem. Soc. 115, 7033-7034 (1993).

36. Noonan, G. M., Fuentes, J. A., Cobley, C. J. \& Clarke, M. L. An Asymmetric Hydroformylation Catalyst that Delivers Branched Aldehydes from Alkyl Alkenes. Angew. Chem. Int. Ed. 51, 2477-2480 (2012).

37. Babin J. E., Whiteker G. T. World patent WO1993003839 (1993).

38. Zhao, B., Peng, X., Wang, Z., Xia, C. \& Ding, K. Modular Chiral Bidentate Phosphonites: Design, Synthesis, and Application in Catalytic Asymmetric Hydroformylation Reactions. Chem. Eur. J. 14, 7847-7857 (2008).

39. Peng, X., Wang, Z., Xia, C. \& Ding, K. Ferrocene-based bidentate phosphonite ligands for rhodium(I)-catalyzed enantioselective hydroformylation. Tetrahedron Lett. 49, 4862-4864 (2008).

40. Kuil, M., Goudriaan, P. E., van Leeuwen, P. W. N. M. \& Reek, J. N. H. Template-induced formation of heterobidentate ligands and their application in the asymmetric hydroformylation of styrene. Chem. Commun. 45, 4679-4681 (2006).

41. Tan, R. et al. Tunable P-Chiral Bisdihydrobenzooxaphosphole Ligands for Enantioselective Hydroformylation. Org. Lett. 18, 3346-3349 (2016).

42. Schmitz, C., Holthusen, K., Leitner, W. \& Franció, G. Highly Regio- and Enantioselective Hydroformylation of Vinyl Esters Using Bidentate Phosphine, P-Chiral Phosphorodiamidite Ligands. ACS Catal. 6, 1584-1589 (2016).

43. Breeden, S., Cole-Hamilton, D. J., Foster, D. F., Schwarz, G. J. \& Wills, M. Rhodium-Mediated Asymmetric Hydroformylation with a Novel Bis(diazaphospholidine) Ligand. Angew. Chem. Int. Ed. 39, 4106-4108 (2000). 
44. Hua, Z., Vassar, V. C., Choi, H. \& Ojima, I. New biphenol-based, fine-tunable monodentate phosphoramidite ligands for catalytic asymmetric transformations. Proc. Natl Acad. Sci. USA 101, 5411-5416 (2004).

45. Wang, X. \& Buchwald, S. L. Rh-Catalyzed Asymmetric Hydroformylation of Functionalized 1,1-Disubstituted Olefins. J. Am. Chem. Soc. 133, 19080-19083 (2011).

46. Sherrill, W. M. \& Rubin, M. Rhodium-Catalyzed Hydroformylation of Cyclopropenes. J. Am. Chem. Soc. 130, 13804-13809 (2008).

47. You, C., Li, S., Li, X., Lv, H. \& Zhang, X. Enantioselective Rh-Catalyzed AntiMarkovnikov Hydroformylation of 1,1-Disubstituted Allylic Alcohols and Amines: an Efficient Route to Chiral Lactones and Lactams. Acs. Catal. 9, 8529-8533 (2019).

48. Dieguez M., Pamies O., Claver C. First successful application of diphosphite ligands in the asymmetric hydroformylation of dihydrofurans. Chem. Commun. 41, 1221-1223 (2005).

49. Gual, A., Godard, C., Castillón, S. \& Claver, C. Highly Efficient Rhodium Catalysts for the Asymmetric Hydroformylation of Vinyl and Allyl Ethers using $C_{1}$-Symmetrical Diphosphite Ligands. Adv. Synth. Catal. 352, 463-477 (2010).

50. Chikkali, S. H. et al. Highly enantioselective hydroformylation of dihydrofurans catalyzed by hybrid phosphine-phosphonite rhodium complexes. Chem. Commun. 46, 1244-1246 (2010).

51. Chikkali, S. H., Bellini, R., de Bruin, B., van der Vlugt, J. I. \& Reek, J. N. H. Highly selective asymmetric Rh-catalyzed hydroformylation of heterocyclic olefins. J. Am. Chem. Soc. 134, 6607-6616 (2012).

52. Fernández-Pérez, H., Benet-Buchholz, J. \& Vidal-Ferran, A. Small Bite-Angle P-OP Ligands for Asymmetric Hydroformylation and Hydrogenation. Org. Lett. 15, 3634-3637 (2013).

53. Horiuchi, H., Ohta, T., Shirakawa, E., Nozaki, K. \& Takaya, H. Asymmetric Hydroformylation of Heterocyclic Olefins Catalyzed by Chiral PhosphinePhosphite-Rh(I) Complexe. J. Org. Chem. 62, 4285-4292 (1997).

54. Axtell, A. T. et al. Highly Regio- and Enantioselective Asymmetric Hydroformylation of Olefins Mediated by 2,5-Disubstituted Phospholane Ligands. Angew. Chem. Int. Ed. 44, 5834-5838 (2005).

55. Li, B., Chen, J., Zhang, Z., Gridnev, I. D. \& Zhang, W. Nickel-Catalyzed Asymmetric Hydrogenation of N-Sulfonyl Imines. Angew. Chem. Int. Ed. 58, 7329-7334 (2019).

56. Llopis, Q., Guillamot, G., Phansavath, P. \& Ratovelomanana-Vidal, V. Enantioselective Synthesis of $\alpha$-Acetal- $\beta^{\prime}$-Amino Ketone Derivatives by Rhodium-Catalyzed Asymmetric Hydrogenation. Org. Lett. 19, 6428-6431 (2017).

57. Hu, Q., Chen, J., Zhang, Z., Liu, Y. \& Zhang, W. Rh-Catalyzed One-Pot Sequential Asymmetric Hydrogenation of a-Dehydroamino Ketones for the Synthesis of Chiral Cyclic trans- $\beta$-Amino Alcohols. Org. Lett. 18, 1290-1293 (2016).

58. Zhang, Z., Tamura, K., Mayama, D., Sugiya, M. \& Imamoto, T. ThreeHindered Quadrant Phosphine Ligands with an Aromatic Ring Backbone for the Rhodium-Catalyzed Asymmetric Hydrogenation of Functionalized Alkenes. J. Org. Chem. 77, 4184-4188 (2012).

59. Ma, M., Hou, G., Wang, J. \& Zhang, X. Rhodium-catalyzed asymmetric hydrogenation of $\beta$-acetylamino acrylonitriles. Tetrahedron.: Asymmetry 22, 506-511 (2011).

60. Yan, Y. \& Zhang, X. A Hybrid Phosphorus Ligand for Highly Enantioselective Asymmetric Hydroformylation. J. Am. Chem. Soc. 128, 7198-7202 (2006).

61. Zhang, X. et al. Synthesis and Application of Modular PhosphinePhosphoramidite Ligands in Asymmetric Hydroformylation: StructureSelectivity Relationship. Chem. Eur. J. 16, 871-877 (2010).

62. Wei, B., Chen, C., You, C., Lv, H. \& Zhang, X. Efficient synthesis of (S,R)-BnYanphos and Rh/(S,R)-Bn-Yanphos catalyzed asymmetric hydroformylation of vinyl heteroarenes. Org. Chem. Front. 4, 288-291 (2017).

63. You, C. et al. Design and Application of Hybrid Phosphorus Ligands for Enantioselective Rh-Catalyzed Anti-Markovnikov Hydroformylation of Unfunctionalized 1,1-Disubstituted Alkenes. J. Am. Chem. Soc. 140, 4977-4981 (2018).
64. Chen, C. et al. Rhodium/Yanphos-Catalyzed Asymmetric Interrupted Intramolecular Hydroaminomethylation of trans-1,2-Disubstituted Alkenes. J. Am. Chem. Soc. 138, 9017-9020 (2016).

65. The result is different with that of our previous work on AHF initiated cascade reaction to form stable hemiacetal (ref. 47), only small amount of hemiacetal was detected on crude ${ }^{1} \mathrm{H}$ NMR in this transfomation, which was unstable on silicon gel column and transformed to aldehyde, giving aldehyde $\mathbf{2 a}$ in $\mathbf{9 4 \%}$ isolated yield.

66. The target product $3 \mathbf{w}$ can be prepared under standard reaction conditions, but it was difficult to obtain pure $3 \mathbf{w}$ due to the low boiling point, thus only the data of $2 \mathbf{w}$ was provided.

67. Krall, J. et al. Molecular Hybridization of Potent and Selective $\gamma$ -

Hydroxybutyric Acid (GHB) Ligands: Design, Synthesis, Binding Studies, and Molecular Modeling of Novel 3-Hydroxycyclopent-1-enecarboxylic Acid (HOCPCA) and trans- $\gamma$-Hydroxycrotonic Acid (T-HCA) Analogs. J. Med. Chem. 60, 9022-9039 (2017).

\section{Acknowledgements}

We are grateful for financial support from the National Natural Science Foundation of China (Grant Nos. 22071188, 21871212), the open foundation of CAS Key Laboratory of Molecular Recognition and Function, the "Double First-Class" project of Shihezi University.

\section{Author contributions}

$\mathrm{H}$. Lv directed the project. S. Li and H. Lv contributed to the concept and design of the experiments. S. Li, Z. Li, M. Li, and L. He performed the experiments and data analysis. S. Li wrote the paper with feedback and guidance from H. Lv and X. Zhang. All authors discussed the experimental results and commented on the paper.

\section{Competing interests}

The authors declare no competing interests.

\section{Additional information}

Supplementary information The online version contains supplementary material available at https://doi.org/10.1038/s41467-021-25569-5.

Correspondence and requests for materials should be addressed to H.L

Peer review information Nature Communications thanks Joost Reek and the other, anonymous, reviewer(s) for their contribution to the peer review of this work.

Reprints and permission information is available at http://www.nature.com/reprints

Publisher's note Springer Nature remains neutral with regard to jurisdictional claims in published maps and institutional affiliations.

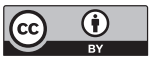

Open Access This article is licensed under a Creative Commons Attribution 4.0 International License, which permits use, sharing, adaptation, distribution and reproduction in any medium or format, as long as you give appropriate credit to the original author(s) and the source, provide a link to the Creative Commons license, and indicate if changes were made. The images or other third party material in this article are included in the article's Creative Commons license, unless indicated otherwise in a credit line to the material. If material is not included in the article's Creative Commons license and your intended use is not permitted by statutory regulation or exceeds the permitted use, you will need to obtain permission directly from the copyright holder. To view a copy of this license, visit http://creativecommons.org/ licenses/by/4.0/.

(C) The Author(s) 2021, corrected publication 2021 